\title{
KORELASI PENGUASAAN STRUKTUR KALIMAT DENGAN KETERAMPILAN MENYUSUN KALIMAT EFEKTIF SISWA KELAS VIII SLTP KARYA BHAKTI MEDAN TAHUN PEMBELAJARAN 2017 - 2018
}

\author{
Abdullah Hasibuan \\ Universitas Muslim Nusantara Al-Washliyah Medan \\ Abdullahhasibuan24@yahoo.com
}

\begin{abstract}
Abstrak
Penulisan ini bertujuan untuk mengetahui Korelasi Penguasaan Struktur Kalimat terhadap Keterampilan Menyusun Kalimat Efektif Siswa Kelas VIII SMP Karya Bhakti Tahun Pembelajaran 2017-2018. Populasi dalam Penelitian ini adalah seluruh siswa kelas VIII SMP Karya Bhakti Tahun Pembelajaran 2017-2018. yang berjumlah 226 siswa. Selanjutnya, untuk menentukan sampel individu yang dapat mewakili setiap kelas digunakan sistem simple random sampling (pengambilan sampel dengan cara acak sederhana). Dengan demikian, jumlah sampel yang diteliti dalam penelitian ini adalah sebanyak 20\% × $226=45,2$ digenapkan menjadi 45 orang. Metode yang digunakan dalam penelitian ini adalah metode deskriptif yaitu metode penelitian yang berusaha mengungkapkan keadaan atau peristiwa sebagaimana mestinya dengan tujuan menjawab atau memecahkan dan menggambarkan gejala-gejala yang terjadi pada saat sekarang atau masalah yang aktual. Dalam penelitian ini, penulis menggunakan alat pengumpulan data berupa tes objektif dan tes menulis kalimat efektif.
\end{abstract}

Kata kunci: struktur kalimat

\begin{abstract}
This writing aims to get the Correlation of Sentence Structure Mastery towards the Skill in Constructing the Effective Sentences by the Eight Grades Students of SMP karya Bhakti in Academic Year 2017-2018. Population of the research is the eight grade students of SMP Karya Bhakti which consist of 226 students. Then, to determine the sample, it can represent every classes using random-sampling system (taking a simple random-sampling). Thus, sample used in this research is $29 \% \times 226=45.2$ to 45 people which fulfilled to 45. The method used in this research is descriptive method which tries to identify the condition or situation like the way it is and aims to answer or solve and describe situation occurred in recent actual problems. In this research, the researcher applies instrument of collecting data in an objective test and test of writing effective sentence.
\end{abstract}

Key word: sentence structure

\section{PENDAHULUAN}

\subsection{Latar Belakang Masalah}

Dalam proses pembelajaran, baik guru maupun siswa sangat memerlukan dan membutuhkan kalimat efektif dalam berkomunikasi, agar materi pelajaran yang disampaikan oleh guru kepada siswanya dapat diterima dengan baik. Selain dalam berkomunikasi, seorang siswa dapat memakai penguasaan kalimat efektif untuk memahami 
soal-soal ujian. Bila seorang siswa memiliki kemampuan menguasai kalimat efektif dengan baik, maka siswa itu dapat dengan mudah menjawab soal-soal ujian tersebut. Misalnya dalam menjawab soal-soal bahasa Indonesia berbentuk cerita, yang diperlukan bagi seorang siswa untuk dapat menjawab soal tersebut adalah dengan adanya pemahaman terhadap penguasaan kalimat efektif dalam soal cerita. Bila seorang siswa telah memahami kalimat dalam soal tersebut maka ia akan lebih mudah mengetahui gambaran jawaban dan soal tersebut.

\subsection{Tujuan Penelitian}

Tujuan penulisan ini adalah Untuk mengetahui penguasaan pola struktur kalimat dan untuk mengetahui korelasi yang signifikan antara penguasaan struktur kalimat dengan keterampilan menyusun kalimat efektif siswa kelas VIII SLTP Karya Bhakti Medan Tahun Pembelajaran 2017 - 2018.

\subsection{Pendekatan Pemecahan Masalah}

Pendekatan pemecahan masalah penulisan ini adalah menggunakan Model Discovery Learning oleh siswa kelas VIII SLTP Karya Bhakti Medan Tahun Pembelajaran 2017 - 2018.

\section{METODE}

Metode yang digunakan dalam penelitian ini adalah metode deskriptif yaitu metode penelitian yang berusaha mengungkapkan keadaan atau peristiwa sebagaimana mestinya dengan tujuan menjawab atau memecahkan dan menggambarkan gejala-gejala yang terjadi pada saat sekarang atau masalah yang aktual. Dalam penelitian ini, penulis menggunakan alat pengumpulan data berupa tes objektif dan tes menulis kalimat efektif.

\section{HASIL DAN PEMBAHASAN}

\subsection{Hasil}

Dalam mendeskripsikan hasil penelitian ini, penulis membaginya dalam tiga pokok bahasan yang merupakan jawaban dari rumusan masalah yang penulis ajukan pada bab sebelumnya. Ketiga pokok bahasa tersebut adalah sebagai berikut:

1. Penguasaan struktur kalimat.

2. Keterampilan menyusun kalimat efektif.

3. Hubungan penguasaan struktur kalimat dengan keterampilan menyusun kalimat efektif.

Demikianlah pengelompokan pembahasan yang penulis kumpul dan susun, dengan tujuan agar pembahasan ini lebih sistematis, terfokus, serta dapat mencapai tujuan penelitian yang diharapkan.

1. Hasil data perhitungan nilai variabel $x$ (penguasaan struktur kalimat)

Setelah dilaksanakan perhitungan tes kepada 45 orang siswa yang menjadi sampel dalam penelitian ini tentang kemampuan mereka dalam menguasai struktur kalimat, selanjutnya penulis mengolah data tersebut menjadi beberapa tahap, yaitu:

a. Menetapkan atau menghitung nilai tiap-tiap sampel untuk variabel $X$, hasil perhitungan tersebut dicantumkan dalam tabel berikut: 
b. Menetapkan atau menghitung nilai tiap-tiap sampel untuk variabel $X$, hasil perhitungan tersebut dicantumkan dalam tabel berikut:

Tabel. 3.1

Tabulasi Data Nilai Jawaban Siswa Mengenai Penguasaan Struktur Kalimat (Variabel X)

\begin{tabular}{|c|c|c|c|}
\hline NO & NAMA SISWA & SKOR & NILAI $(\mathbf{X})$ \\
\hline 1 & Ahmad Fauzi Harahap & 20 & 100 \\
\hline 2 & Alda Umayrah & 20 & 100 \\
\hline 3 & Arnudi Bare & 16 & 80 \\
\hline 4 & Arum Gayatri & 20 & 100 \\
\hline 5 & Ayu Sekar & 20 & 100 \\
\hline 6 & Ayuni Aprika & 19 & 95 \\
\hline 7 & Benu Sihombing & 20 & 100 \\
\hline 8 & Budi Wiranto Panggabean & 20 & 100 \\
\hline 9 & Dinda Yolanda Bahri & 20 & 100 \\
\hline 10 & Dini Oetari & 20 & 100 \\
\hline 11 & Erick Albert & 18 & 90 \\
\hline 12 & Fhika Ghea & 18 & 90 \\
\hline 13 & Frans J. Sihaloho & 18 & 90 \\
\hline 14 & Friska Anggraini & 20 & 100 \\
\hline 15 & Gomos & 17 & 85 \\
\hline 16 & Hery Hartono & 20 & 100 \\
\hline 17 & Hesti Veronika & 20 & 100 \\
\hline 18 & Imam Setiawan & 20 & 100 \\
\hline 19 & Ina Triana & 20 & 100 \\
\hline 20 & Indah Mugiasih & 17 & 85 \\
\hline 21 & Jalu Suragil & 20 & 100 \\
\hline 22 & Julio Hutabarat & 16 & 80 \\
\hline 23 & Kiki Mahyani Nasution & 18 & 90 \\
\hline 24 & Lolo Karina Berutu & 19 & 95 \\
\hline 25 & Maudira Harifa & 17 & 85 \\
\hline 26 & Meysi Agustin & 18 & 90 \\
\hline 27 & Michael Chang & 20 & 100 \\
\hline 28 & Putri Hanfaha & 16 & 80 \\
\hline 29 & Putri Latifah & 20 & 100 \\
\hline 30 & Regita & 18 & 90 \\
\hline 31 & Rekanda Bangun & 18 & 90 \\
\hline 32 & Riyan Fartawijaya & 19 & 95 \\
\hline 33 & Rizky Dava & 20 & 100 \\
\hline 34 & Roy Martin & 18 & 90 \\
\hline 35 & Ruth Margaretha & 17 & 85 \\
\hline 36 & Sapta Aditya & 17 & 85 \\
\hline 37 & Sari Darma Pertiwi & 20 & 100 \\
\hline 38 & Sella Aulia & 20 & 100 \\
\hline 39 & Sintia Silagan & 16 & 80 \\
\hline 40 & Sri Audri Prastika & 16 & 80 \\
\hline 41 & Stefanus Rinding & 15 & 75 \\
\hline 42 & Syafika & 16 & 80 \\
\hline 43 & Tamara Tria Putri & 20 & 100 \\
\hline 44 & Tiara Syahfitri & 20 & 100 \\
\hline 45 & Yosua & 19 & 95 \\
\hline \multicolumn{2}{|c|}{ Jumlah $(\Sigma X)$} & 836 & 4180 \\
\hline
\end{tabular}

Tabel di atas memperlihatkan jumlah nilai yang diperoleh seluruh siswa dalam penyebaran angket tentang penguasaan struktur kalimat adalah 4180 . 


\section{c. Menghitung mean dan standar deviasi}

Setelah diketahui nilai setiap siswa, maka nilai tersebut dijumlahkan untuk mean. Dalam hal ini penulis menggunakan rumus:

$$
\begin{aligned}
M & =\frac{\sum X}{N} \\
M & =\frac{4180}{45}
\end{aligned}
$$

$\mathrm{M}=92,89$

Setelah mean diketahui, maka langkah berikutnya adalah mencari standar deviasinya. Untuk standar deviasi penulis menggunakan rumus:

$$
\mathrm{SD}=\sqrt{\frac{\sum X^{2}}{N}}
$$

Untuk mencari standar deviasi dibutuhkan tabel kerja sebagai berikut:

Tabel. 3.2

\begin{tabular}{|c|c|c|c|c|c|}
\hline NO & NAMA SISWA & SKOR & NILAI (X) & $\mathbf{X}^{\prime}$ & $X^{\prime 2}$ \\
\hline 1 & Ahmad Fauzi Harahap & 20 & 100 & 7,11 & 50,55 \\
\hline 2 & Alda Umayrah & 20 & 100 & 7,11 & 50,55 \\
\hline 3 & Arnudi Bare & 16 & 80 & $-12,89$ & 166,15 \\
\hline 4 & Arum Gayatri & 20 & 100 & 7,11 & 50,55 \\
\hline 5 & Ayu Sekar & 20 & 100 & 7,11 & 50,55 \\
\hline 6 & Ayuni Aprika & 19 & 95 & 2,11 & 4,45 \\
\hline 7 & Benu Sihombing & 20 & 100 & 7,11 & 50,55 \\
\hline 8 & Budi Wiranto Panggabean & 20 & 100 & 7,11 & 50,55 \\
\hline 9 & Dinda Yolanda Bahri & 20 & 100 & 7,11 & 50,55 \\
\hline 10 & Dini Oetari & 20 & 100 & 7,11 & 50,55 \\
\hline 11 & Erick Albert & 18 & 90 & $-2,89$ & 8,35 \\
\hline 12 & Fhika Ghea & 18 & 90 & $-2,89$ & 8,35 \\
\hline 13 & Frans J. Sihaloho & 18 & 90 & $-2,89$ & 8,35 \\
\hline 14 & Friska Anggraini & 20 & 100 & 7,11 & 50,55 \\
\hline 15 & Gomos & 17 & 85 & $-7,89$ & 62,25 \\
\hline 16 & Hery Hartono & 20 & 100 & 7,11 & 50,55 \\
\hline 17 & Hesti Veronika & 20 & 100 & 7,11 & 50,55 \\
\hline 18 & Imam Setiawan & 20 & 100 & 7,11 & 50,55 \\
\hline 19 & Ina Triana & 20 & 100 & 7,11 & 50,55 \\
\hline 20 & Indah Mugiasih & 17 & 85 & $-7,89$ & 62,25 \\
\hline 21 & Jalu Suragil & 20 & 100 & 7,11 & 50,55 \\
\hline 22 & Julio Hutabarat & 16 & 80 & $-12,89$ & 166,15 \\
\hline 23 & Kiki Mahyani Nasution & 18 & 90 & $-2,89$ & 8,35 \\
\hline 24 & Lolo Karina Berutu & 19 & 95 & 2,11 & 4,45 \\
\hline 25 & Maudira Harifa & 17 & 85 & $-7,89$ & 62,25 \\
\hline 26 & Meysi Agustin & 18 & 90 & $-2,89$ & 8,35 \\
\hline 27 & Michael Chang & 20 & 100 & 7,11 & 50,55 \\
\hline 28 & Putri Hanfaha & 16 & 80 & $-12,89$ & 166,15 \\
\hline 29 & Putri Latifah & 20 & 100 & 7,11 & 50,55 \\
\hline 30 & Regita & 18 & 90 & $-2,89$ & 8,35 \\
\hline 31 & Rekanda Bangun & 18 & 90 & $-2,89$ & 8,35 \\
\hline 32 & Riyan Fartawijaya & 19 & 95 & 2,11 & 4,45 \\
\hline 33 & Rizky Dava & 20 & 100 & 7,11 & 50,55 \\
\hline 34 & Roy Martin & 18 & 90 & $-2,89$ & 8,35 \\
\hline 35 & Ruth Margaretha & 17 & 85 & $-7,89$ & 62,25 \\
\hline 36 & Sapta Aditya & 17 & 85 & $-7,89$ & 62,25 \\
\hline 37 & Sari Darma Pertiwi & 20 & 100 & 7,11 & 50,55 \\
\hline 38 & Sella Aulia & 20 & 100 & 7,11 & 50,55 \\
\hline
\end{tabular}

Tabel Kerja Mencari Standar Deviasi Variabel X (Variabel X) 


\begin{tabular}{|c|l|c|c|c|c|}
\hline 39 & Sintia Silagan & 16 & 80 & $-12,89$ & 166,15 \\
\hline 40 & Sri Audri Prastika & 16 & 80 & $-12,89$ & 166,15 \\
\hline 41 & Stefanus Rinding & 15 & 75 & $-17,89$ & 320,05 \\
\hline 42 & Syafika & 16 & 80 & $-12,89$ & 166,15 \\
\hline 43 & Tamara Tria Putri & 20 & 100 & 7,11 & 50,55 \\
\hline 44 & Tiara Syahfitri & 20 & 100 & 7,11 & 50,55 \\
\hline 45 & Yosua & 19 & 95 & 2,11 & 4,45 \\
\hline \multicolumn{2}{|r|}{ Jumlah $(\boldsymbol{\Sigma} \mathbf{X})$} & $\mathbf{8 3 6}$ & $\mathbf{4 1 8 0}$ & $\mathbf{0}$ & $\mathbf{2 7 7 4 , 3 5}$ \\
\hline
\end{tabular}

Berdasarkan tabel di atas, maka langkah selanjutnya adalah memasukkan jumlah $\mathrm{X}^{\prime 2}$ ke dalam rumus untuk mencari standar deviasi, yaitu.

$$
\begin{aligned}
\mathrm{SD} & =\sqrt{\frac{\sum X^{\prime 2}}{N}} \\
\mathrm{SD} & =\sqrt{\frac{2774,35}{45}} \\
\mathrm{SD} & =61,65
\end{aligned}
$$

Berdasarkan perhitungan di atas, diketahui bahwa standar deviasi

\section{Tabel.3.3}

Tabel Kerja Mencari Nilai Akhir Siswa untuk Variabel X

\begin{tabular}{|c|c|c|}
\hline Skala Sigma & Skala Nilai & Skala Skor \\
\hline 2.25 SD & 100 & Mean + 2.25 SD \\
1.75 SD & 90 & Mean + 1.75 SD \\
1.25 SD & 80 & Mean + 1.25 SD \\
0.75 SD & 70 & Mean + 0.75 SD \\
\hline 0.25 SD & 60 & Mean + 0.25 SD \\
-0.25 SD & 50 & Mean - 0.25 SD \\
-0.75 SD & 40 & Mean - 0.75 SD \\
-1.25 SD & 30 & Mean - 1.25 SD \\
-1.75 SD & 20 & Mean - 1.75 SD \\
-2.25 SD & 10 & Mean - 2.25 SD \\
\hline
\end{tabular}

Pedoman tabel di atas dipindahkan ke dalam tabel konversi untuk menentukan nilai akhir siswa sebagaimana tabel berikut ini.

Tabel 3.4

Konversi Nilai Siswa untuk Variabel X dalam Skala Nilai 10 - 100

\begin{tabular}{|c|c|c|}
\hline Skala Sigma & Skala Nilai & Skala Skor \\
\hline $2.25 \mathrm{SD}$ & 100 & $92,89+(2.25 \times 61,65)=231,60$ \\
$1.75 \mathrm{SD}$ & 90 & $92,89+(1.75 \times 61,65)=231,35$ \\
\hline
\end{tabular}




\begin{tabular}{|r|c|c|}
\hline $1.25 \mathrm{SD}$ & 80 & $92,89+(1.25 \times 61,65)=169,95$ \\
$0.75 \mathrm{SD}$ & 70 & $92,89+(0.75 \times 61,65)=139,13$ \\
$0.25 \mathrm{SD}$ & 60 & $92,89+(0.25 \times 61,65)=108,30$ \\
$-0.25 \mathrm{SD}$ & 50 & $92,89-(0.25 \times 61,65)=77,48$ \\
$-0.75 \mathrm{SD}$ & 40 & $92,89-(0.75 \times 61,65)=46,65$ \\
$-1.25 \mathrm{SD}$ & 30 & $92,89-(1.25 \times 61,65)=15,83$ \\
$-1.75 \mathrm{SD}$ & 20 & $92,89-(1.75 \times 62,65)=-16,75$ \\
$-2.25 \mathrm{SD}$ & 10 & $92,89-(2.25 \times 62,65)=-48,07$ \\
\hline
\end{tabular}

Berdasarkan tabel di atas, maka dapat ditentukan nilai akhir siswa sesuai dengan skor mentah yang diperolehnya. Untuk lebih jelasnya dapat dilihat pada tabel berikut:

Tabel 3.5

Nilai Akhir Siswa untuk Variabel X

\begin{tabular}{|c|c|c|c|c|c|}
\hline \multirow{2}{*}{ No } & \multirow{2}{*}{ Nama Siswa } & \multirow{2}{*}{ Skor } & \multicolumn{2}{|c|}{ Skala Terdekat } & \multirow{2}{*}{ Nilai Akhir } \\
\hline & & & Skor & Nilai & \\
\hline 1 & Ahmad Fauzi Harahap & 20 & 231,60 & 100 & 100 \\
\hline 2 & Alda Umayrah & 20 & 231,60 & 100 & 100 \\
\hline 3 & Arnudi Bare & 16 & 108,30 & 60 & 60 \\
\hline 4 & Arum Gayatri & 20 & 231,60 & 100 & 100 \\
\hline 5 & Ayu Sekar & 20 & 231,60 & 100 & 100 \\
\hline 6 & Ayuni Aprika & 19 & 200,78 & 90 & 90 \\
\hline 7 & Benu Sihombing & 20 & 231,60 & 100 & 100 \\
\hline 8 & $\begin{array}{l}\text { Budi Wiranto } \\
\text { Panggabean }\end{array}$ & 20 & 231,60 & 100 & 100 \\
\hline 9 & Dinda Yolanda Bahri & 20 & 231,60 & 100 & 100 \\
\hline 10 & Dini Oetari & 20 & 231,60 & 100 & 100 \\
\hline 11 & Erick Albert & 18 & 169,95 & 80 & 80 \\
\hline 12 & Fhika Ghea & 18 & 169,95 & 80 & 80 \\
\hline 13 & Frans J. Sihaloho & 18 & 169,95 & 80 & 80 \\
\hline 14 & Friska Anggraini & 20 & 231,60 & 100 & 100 \\
\hline 15 & Gomos & 17 & 139,13 & 70 & 70 \\
\hline 16 & Hery Hartono & 20 & 231,60 & 100 & 100 \\
\hline 17 & Hesti Veronika & 20 & 231,60 & 100 & 100 \\
\hline 18 & Imam Setiawan & 20 & 231,60 & 100 & 100 \\
\hline 19 & Ina Triana & 20 & 231,60 & 100 & 100 \\
\hline 20 & Indah Mugiasih & 17 & 139,13 & 70 & 70 \\
\hline 21 & Jalu Suragil & 20 & 231,60 & 100 & 100 \\
\hline 22 & Julio Hutabarat & 16 & 108,30 & 60 & 60 \\
\hline 23 & Kiki Mahyani Nasution & 18 & 169,95 & 80 & 80 \\
\hline 24 & Lolo Karina Berutu & 19 & 200,78 & 90 & 90 \\
\hline 25 & Maudira Harifa & 17 & 139,13 & 70 & 70 \\
\hline 26 & Meysi Agustin & 18 & 169,95 & 80 & 80 \\
\hline 27 & Michael Chang & 20 & 231,60 & 100 & 100 \\
\hline 28 & Putri Hanfaha & 16 & 108,30 & 60 & 60 \\
\hline 29 & Putri Latifah & 20 & 231,60 & 100 & 100 \\
\hline 30 & Regita & 18 & 169,95 & 80 & 80 \\
\hline 31 & Rekanda Bangun & 18 & 169,95 & 80 & 80 \\
\hline 32 & Riyan Fartawijaya & 19 & 200,78 & 90 & 90 \\
\hline 33 & Rizky Dava & 20 & 231,60 & 100 & 100 \\
\hline 34 & Roy Martin & 18 & 169,95 & 80 & 80 \\
\hline 35 & Ruth Margaretha & 17 & 139,13 & 70 & 70 \\
\hline 36 & Sapta Aditya & 17 & 139,13 & 70 & 70 \\
\hline 37 & Sari Darma Pertiwi & 20 & 231,60 & 100 & 100 \\
\hline 38 & Sella Aulia & 20 & 231,60 & 100 & 100 \\
\hline
\end{tabular}




\begin{tabular}{|c|l|c|c|c|c|}
\hline 39 & Sintia Silagan & 16 & 108,30 & 60 & 60 \\
\hline 40 & Sri Audri Prastika & 16 & 108,30 & 60 & 60 \\
\hline 41 & Stefanus Rinding & 15 & 77,48 & 50 & 50 \\
\hline 42 & Syafika & 16 & 108,30 & 60 & 60 \\
\hline 43 & Tamara Tria Putri & 20 & 231,60 & 100 & 100 \\
\hline 44 & Tiara Syahfitri & 20 & 231,60 & 100 & 100 \\
\hline 45 & Yosua & 19 & 200,78 & 90 & 90 \\
\hline \multicolumn{2}{|c|}{ JUMLAH } & & $\mathbf{8 5 6 0}$ \\
\hline
\end{tabular}

Berdasarkan keterangan dari tabel di atas, maka diketahui bahwa rata-rata dari seluruh jumlah nilai akhir tentang penguasaan siswa terhadap struktur kalimat adalah $3860: 45=85,77$. Dengan demikian, untuk mengetahui jumlah siswa yang memperoleh nilai 10 sampai 100 adalah sebagai berikut:

$\begin{array}{llll}\text { 1. Nilai } 100 & = & 21 \\ \text { 2. Nilai } 90 & \begin{array}{l}\text { orang } \\ \text { orang }\end{array} & 4 \\ \text { 3. Nilai } 80 & & = & 8 \\ \text { 4. Nilai } 70 & \text { orang } & = \\ \text { 5. Nilai } 60 & \text { orang } & 5 \\ \text { 6. Nilai } 50 & = & 6 \\ \text { 7. Nilai } 40 & \text { orang } & \\ & & \text { orang } & \\ & & \text { orang } & \end{array}$

8. Nilai 30 $=\quad 0$

orang

9. Nilai $20=0$

orang

10. Nilai $10=0$

orang

e. Menghitung persentase nilai akhir dari variabel $X$ (Penguasaan Struktur Kalimat)

Berdasarkan jumlah siswa yang memperoleh nilai akhir, maka dapat diketahui nilai akhir siswa tersebut dengan menggunakan rumus :

$$
\text { Persentase }=\frac{A}{N} 100 \%
$$

Keterangan:

$$
\begin{aligned}
& \text { A } \quad=\text { Nilai } \\
& \mathrm{N} \quad=\text { Jumlah } \\
& \text { sampel }
\end{aligned}
$$

Untuk lebih jelasnya, dapat dilihat pada tabel berikut

Tabel. 3.6

Persentase Nilai tentang Penguasaan Struktur Kalimat

\begin{tabular}{|c|c|c|c|}
\hline Nilai & Jumlah Sampel & Persentase & Kategori \\
\hline 100 & 21 & 46,67 & Sangat Memuaskan \\
\hline 90 & 4 & 8,89 & Memuaskan \\
\hline 80 & 8 & 17,78 & Sangat Baik \\
\hline 70 & 5 & 11,11 & Baik \\
\hline 60 & 6 & 13,33 & Kukup \\
\hline 50 & 1 & 2,22 & Sangat Kurang \\
\hline 40 & - & - & Sangat Kurang \\
\hline 30 & - & - & Sangat Kurang \\
\hline 20 & - & - & Sangat Kurang \\
\hline 10 & - & - & \\
\hline
\end{tabular}


Bila dilihat dari tabel di atas, dapat diketahui tentang penguasaan struktur kalimat, yang menyatakan bahwa mayoritas siswa yang menjadi sampel dalam penelitian ini memperoleh nilai 10 yang terletak pada kategori "sangat memuaskan" yaitu sebanyak 21 orang atau 46,67 $\%$ dari jumlah sampel yang ada pada penelitian ini (45 orang).

\section{KESIMPULAN.}

Simpulan yang dapat dipaparkan dalam penelitian ini yaiyu; Dengan baiknya penguasaan siswa tentang struktur kalimat, maka sedikit banyaknya akan mampu meningkatkan kemampuan mereka dalam keterampilan menyusun kalimat efektif dan dari hasil data teks yang disebarkan kepada 45 orang responden yang menjadi sampel dalam penelitian ini, didapati hasil data untuk variabel $X$ (penguasaan struktur kalimat ), mayoritas siswa memiliki/ dapat menguasai teori kalimat tersebut, sehingga mereka memiliki keterampilan menyusun kalimat efektif berbentuk teks (variabel Y).

\section{DAFTAR PUSTAKA}

Badudu, 1985. Pelak-Pelik Bahasa Indonesia, Bandung: Pustaka Prima.

Hadi, Sutrisno, 1990. Metodologi Research, Yogyakarta: Andi Offset

Keraf Gorys, 1973. Komposisi: Sebuah Pengantar Kemahiran Bahasa. Flores: Nusa Indah. 1980. Eksposisi dan Deskripsi. Ende Flora: Nusa Indah.

1984. Komposisi. Jakarta: Nusa Indah.

Lubis, Hamid Hasan. 1989. Sintaksis, Medan: FBS IKIP.

Pusat Bahasa Departemen Pendidikan Nasional, 2005. Kamus Besar Bahasa Indonesia, Jakarta: Balai Pustaka.

Razak, Abdul. 1988. Kalimat Efektif. Jakarta: Gramedia.

Samosir, Solo. 1984. Pengajaran Bahasa dan Sastra. Jakarta: Gramedia.

Sudjana, 2005. Metode Statistika. Bandung: Tarsito. 